\title{
Is painting by elephants in zoos as enriching as we are led to believe?
}

The relationship between the activity of painting and performance of stereotyped and other stress-related behaviour was investigated in four captive Asian elephants at Melbourne Zoo, Australia. The activity involved the elephant being instructed to paint on a canvas by its keeper in front of an audience. Painting by elephants in zoos is commonly believed to be a form of enrichment, but this assumption had not been based on any systematic research. If an activity is enriching we would expect stress-related behaviour to be reduced but we found no evidence of the elephants anticipating the painting activity and no effect on the performance of stereotyped or other stress-related behaviour either before or after the painting session. This indicates that the activity does not fulfil one of the main aims of enrichment. However, if an elephant was not selected to paint on a given day this was associated with higher levels of non-interactive behaviour, a possible indicator of stress. Behavioural observations associated with ear, eye and trunk positions during the painting session showed that the elephant's attentiveness to the painting activity or to the keeper giving instruction varied between individuals. Apart from positive reinforcement from the keeper, the results indicated that elephants gain little enrichment from the activity of painting. Hence, the benefits of this activity appear to be limited to the aesthetic appeal of these paintings to the people viewing them. 
2 Authors: Megan English ${ }^{1,2}$, Gisela $\operatorname{Kaplan}^{1}$ and Lesley J. Rogers ${ }^{1}$

3 1. Centre for Neuroscience and Animal Behaviour, University of New England, Armidale, 4 NSW 2351, Australia.

5 2. Centre for Biodiversity and Restoration Ecology, School of Biological Sciences

6 Victoria University of Wellington, New Zealand

7

8

9

10

11 Megan English

12 email: megan.english@vuw.ac.nz
13

14

15

16

17

18

19

20

21

22

23

24

25

26

27

28

29

30

31

32

33

34

35

36

37

38

39

40

41

42

43

44

45 


\section{Introduction}

52 Since the 1960's elephants have been considered intelligent (Rensch, 1957; Gordon, 1966), with

53 significant research about their cognitive abilities taking place in recent years (Shoshani, Kupsky

54 \& Marchant, 2006; Bradshaw \& Schore, 2007; Hart, Hart \& Pinter-Wollman, 2008; Byrne, Bates

$55 \&$ Moss, 2009). It is now clear that elephants can solve problems (Foerder et al., 2011), use tools

56 (Chevalier-Skolnikoff \& Liska, 1993; Hart \& Hart, 1994; Hart et al., 2001) have empathy (Bates,

57 2008; Byrne et al., 2008), recognise human faces (McComb et al., 2014), show the complex

58 behaviour of self-recognition (Plotnik, de Waal \& Reiss, 2006; Plotnik et al. 2010, 2011) and

59 have a high level of social complexity (Poole, 1996; Schulte, 2000; Payne, 2003; Wittemyer et

60 al., 2005). It is therefore a reasonable assumption that elephants may be able to learn to paint and

61 they certainly would have no difficulty in using the trunk to direct a paint brush.

62 Evidence of their complex communication (Poole et al., 1988; Langbauer, 2000) in stable

63 social relationships (Moss \& Poole, 1983; Nair et al., 2009) and their phenomenal memories

64 (Moss, 1988), particularly of spaces and resources, has been demonstrated repeatedly. Questions

65 have been raised how such animals, that are self-aware and remember their own past, are affected

66 by captivity and by traumatic events in the wild (Bradshaw et al., 2005; Machowski et al., 2013).

67 Indeed, animals now known to be as complex in their comprehension of their surroundings raise

68 additional questions on how to avoid boredom and stress by confinement. While such

69 establishments as zoos and sanctuaries are expected to provide each species with enrichment

70 adequate to enhance species-specific psychological and physiological wellbeing (Hediger, 1950;

71 Carlstead \& Shepherdson, 2000; Mellen \& MacPhee, 2005; Veasey, 2006), it is clear that

72 elephants present very challenging problems. They are large in size, and space in zoos may be too 
73 limited to be adequate. Their natural feeding habits usually occupy much of the day (and in large

74 quantities) and their browsing habits in the wild usually make them cover large distances

75 (Samansiri \& Weerakoon, 2007). Adequate compensations for such habits and skills pose almost

76 insurmountable problems and it as clear to many that such enrichment ought to be more varied

77 and complex than just hiding food (Lair 1997, Wiedenmayer 1998). Occupying them in some

78 games or varied routines is certainly a strategy that many zoos have adopted. One of the activities

79 assumed to provide enrichment to captive elephants is allowing them to paint on canvas using

80 coloured paints and brushes under the guidance of zoo keepers (Gilbert, 1990; Tennesen 1998;

81 Rogers \& Kaplan, 2007).

According to Forthman \& Ogden (1992), a reduction in stress can be realized by creating

83 interesting environments and activities that encourage natural behaviour; for example, by

84 providing animals with opportunities to solve problems, to make choices and to obtain a sense of

85 control over their environment. Enrichment strategies vary widely according to species, staff

86 availability and the ingenuity of their keepers. With a few exceptions (and elephant management

87 is one of them; Sevenich et al. 1998; Shepherdson 1999; Stoinski et al. 2000) it has rarely been

88 tested in a rigorous fashion as to whether these measures purported to be beneficial actually are.

89 Many enrichment programs, sometimes of necessity, are highly contrived and find no equivalent

90 in a species' natural environment. Whether contrived or not, in such cases one might argue that

91 the end justifies the means if it can be shown that there is a measurable benefit to reduce stress

92 and abnormal behaviour, often a consequence of prolonged stress. The question is whether the

93 activity of painting is an activity that might be enjoyable for elephants? While highly imaginative

94 as an idea, of course, as far as we know anything equating painting does not occur in the wild,

95 although the trunk has been shown to be used for many purposes (Shoshani, 1997). 
In order to establish whether painting benefits elephants, and is therefore a form of

97 enrichment, some key questions needed to be addressed. Does painting change stress behaviour

98 in any way? If so, is there a difference in stereotyped movements and reduced social interaction

99 on the days when an elephant paints compared to days when it does not? Painting might appeal

100 to the higher cognitive abilities of elephants, as it involves the learnt use of a tool. The tool-using

101 aspect of painting could, therefore, be stimulating to a species that uses tools in the natural

102 environment (Chevalier-Skolnikoff \& Liska, 1993; Hart \& Hart, 1994; Shoshani, 1997). On the

103 other hand, because the act of painting is not a typical behaviour for elephants it could itself

104 cause stress. A way of assessing stress behaviourally would be to measure stereotyped and

105 abnormal behaviour before, during and after painting, provided any stereotypical or abnormal

106 behaviour had been noted in the elephants to be observed.

107 Captive animals often develop stereotyped behaviours that are rarely observed in wild or

108 free-ranging animals (Boorer, 1972). A stereotypy has been defined as a repetitive, invariant

109 behaviour pattern with no obvious goal or function (Odberg, 1987; Mason, 1991). Mason \&

110 Latham (2004) found that situations in which stereotyped behaviour occurs are usually a sign of

111 poor welfare conditions. However, those individuals performing the stereotyped behaviour,

112 which may be related to an earlier experience of a stressful situation (Schmid et al., 2001), often

113 have lower levels of stress hormones (e.g. cortisol) than those not performing stereotyped

114 behaviour (Mason \& Latham, 2004). There is ample evidence that anticipation of being fed

115 (Friend, 1999; Rees, 2004) or of other events important to a captive elephant (Friend; 1999; Kurt

$116 \&$ Garai, 2002) may induce stereotypies which occur because arousal levels increase and the

117 animal is unable to do anything but wait until the anticipated activity takes place (Elzanowski \&

118 Sergiel, 2006). It has also been found that low temperature can trigger an increase in stereotypic 
119 behaviour if the elephants in question have had a traumatic past (Rees, 2004) suggesting that

120 seemingly unrelated events can alter the expression of distress quite rapidly in elephants.

121 Elephants display a number of typical stereotyped patterns of behaviour. Weaving

122 behaviour performed by both Asian and African elephants in captivity consists of swaying the

123 head from side to side while transferring the weight from one foreleg to another, and swinging

124 the trunk at the same time. Head bobbing consists of repeated up and down or forward and

125 backward rocking of the head while standing still, and pacing in their enclosures (Kiley-

126 Worthington, 1990; Langbauer, 2000; Rees, 2004). We were interested in measuring whether the

127 prevalence and intensity of these stereotypies and other stress related behaviour varied before and

128 after painting sessions.

129 Natural body postures in elephants have also been described in great detail and have been

130 known for a long time, indicating that the position of ears, movements and activities of the trunk

131 and the tail may have very specific meanings (Kuhme, 1963; McKay, 1973) and are useful

132 devices for scoring details of an elephant's state of mind and mood.

\section{METHODS}

\section{Focal species and enclosures}

136 This study was conducted between October 2007 to February 2008, observing four female

137 elephants housed at Melbourne Zoo. Ethics approval was given by the Animal Ethics Committee

138 at the University of New England (AEC07/096). All four elephants were of Asian origin

139 (Elephas maximus); three from Thailand (Elephas maximus indicus) (hereafter referred to as

140 elephants A, B and C) and one Malaysian (Elephas maximus sumatranus) (hereafter referred to as

141 elephant D). Each elephant had different levels of experience in painting: A (7 years old), B (10 
142 years old) and C (15 years old) had been painting for 2-3 years and D (33 years old) had been

143 painting for approximately 8 years. At the onset of this study, A, B and C had been at Melbourne

144 Zoo for one year and D for 30 years.

145 The elephants in this study did not constitute a selected sample but represented the entire

146 cohort of participants in painting sessions at Melbourne Zoo at the time; i.e. every elephant was

147 scored that was involved in painting during the study period. The only male housed at Melbourne

148 was at that time not trained in performing painting and was therefore not involved in this study.

149 Which elephants were to perform painting on a given day was decided by the keeper minutes

150 before the elephants were to be moved to the painting enclosure and the choice was based on 151 general demeanour.

152 The building in which painting took place, also used for medical checks, treatment 153 administration, washing, feeding, and obedience task training, contained four stalls: the stalls in 154 which painting took place were $6 \mathrm{~m} \times 6 \mathrm{~m}$. The elephants were always taken into the building for 155 the painting session in the same pairs (either $A / B$ or $C / D$ ), and then separated into different stalls 156 for the painting session. One elephant was given food while the other painted. Each painting 157 session lasted less than 5 minutes.

\section{Behavioural data collection}

159 Daily behavioural scoring took place at three intervals: from 10.00am to 11.00am (3-4 hours

160 before the painting session), from $1.00 \mathrm{pm}$ to $2.00 \mathrm{pm}$ ( 1 hour before the painting session) and

161 from $4.00 \mathrm{pm}$ to $5.00 \mathrm{pm}$ (1 hour after the painting session). This occurred twice per week. A focal

162 subject was selected for scoring, in pseudo-random order, and its behaviour was recorded in all

163 sessions that day regardless of whether it was selected to paint or not. For each elephant, four

164 days were scored in each of the following conditions: (1) days when the focal elephant painted, 
165 (2) days when the focal elephant did not paint and other elephants did and (3) days when no 166 painting took place.

167 The behaviour was scored using two techniques: (1) videorecorded, and later replayed to 168 score behaviour, and (2) direct observation within 5-20 $\mathrm{m}$ of the focal elephant. Minute-interval 169 sampling was used to record various behaviours that occurred for longer durations (for example

170 social interaction, stereotyped or non-interactive behaviour), and event recording was used for 171 behaviour that occurred infrequently and less often (for example, vocalisations).

172 The following behaviour was scored (see Kuhme, 1963; McKay, 1973; Poole \& Granli, 2009):

173 1) Interactive behaviour - involving social interactions with conspecifics including visual and 174 tactile displays during affiliation or playful interactions. For example, using the trunk to smell 175 and touch another elephant, ear-flapping, tail-raising without defecation, tail slapping against 176 body or holding ears forward $\left(45^{\circ}-90^{\circ}\right.$ from body).

177 2) Non-interactive behaviour was comprised of standing still with the trunk tip touching the 178 ground, ears in neutral position $\left(<45^{\circ}\right.$ from body), tail in a neutral position and separate from 179 other elephants. Head is upright and eyes open to differentiate from sleeping.

180 3) Independent activity included exploratory behaviour, not involving conspecific interaction, 181 such as using the trunk to smell, touch or manipulate an object, placing the ears forward $\left(45^{\circ}-90^{\circ}\right.$ 182 from body) and raising the tail without defecation.

183 4) Stereotyped or abnormal behaviour such as weaving, pacing, head-bobbing, trunk-swinging

184 and other repetitive or abnormal behaviours. These were considered to be stereotyped if they 185 were repeated in quick succession and appeared to serve no function related to their external 186 environment. 
187 5) Waiting at the door or gate to the indoor enclosure where painting took place. This behaiour

188 reflected anticipation and might indicate if an elephant voluntarily put itself in a position nearer

189 to its keepers and to the area where it would paint.

190 6) Vocalisations were scored using event sampling. These included chirps, growls, snorts,

191 trumpets and roars.

\section{Behaviour scored during the painting session}

193 Painting involved following instructions from the keeper and performing the task in front of an

194 audience. A canvas was held in front of the elephant at their eye level and at a distance where the

195 elephant could reach it by full or partial extension of the trunk. Either the keepers, or selected

196 members of the public, chose the colour of the paint. The brush was then handed to the elephant,

197 which it then held with its trunk. Instruction was given by the keeper to the elephant when to

198 start and stop painting, and when to give the brush to the keeper for colour changes. Positive

199 reinforcement was usually given throughout the activity in the form of food and verbal

200 encouragement from the keeper.

201 Both elephants in the pair that were taken into the building for painting had their

202 behaviour recorded. Painting sessions took place once a week between 2.30pm and 3.00pm.

203 Each session lasted between 2 and 5 minutes, and was a highly structured event. For example,

204 when the elephant was not holding the paintbrush and awaiting the next instruction it was

205 directed to rest its trunk tip on the ground (elephants C/D) or to raise its trunk and rest the tip on

206 the trunk base (elephants A/B). A total of 16 painting sessions were recorded (four per elephant). 
210 1) Ear positions were recorded to indicate arousal level (Kuhme, 1963; McKay, 1973). The

211 amount of time that the elephant spent with its ears held in particular positions during the 212 painting session was quantified. Positions included, ears forward $\left(45^{\circ}-90^{\circ}\right.$ from body -indicating

213 a high level of arousal), ears neutral ( $<45^{\circ}$ from body) and ears against the body (commonly a

214 sign of apprehension and submission- Kuhme, 1963). Ear flapping was not recorded due to the 215 difficulty in differentiating whether this was a reaction to the activity or for thermoregulation.

216 2) Gaze direction indicated whether the elephant was looking at the painting, the audience or the

217 keeper giving commands. Direction of gaze was determined by recording the eye white position.

218 For example, if the white of the left eye was nasal and/ or the eye white of the right eye was

219 temporal, the elephant was viewing the keeper, who always stood on the elephant's left side.

220 Stereotyped and abnormal behaviour was not recorded during the painting session due the short

221 period of time during which there was very little opportunity for the elephants to behave in any

222 way other than that determined by the keeper's instructions.

\section{Data analyses}

224 Behavioural scores were anlaysed using the SPSS 16.00 statistical programme. Initially, for each 225 behaviour, we compared replicates (four per elephant) at the three different times of day 226 (morning, midday and afternoon) using a repeated measures General Linear Model (where 227 replicates were the repeated measures and time of day the factor). Then condition ( $\mathrm{P}=$ focal 228 elephant paints, $\mathrm{NP}=$ no elephant paints and $\mathrm{OP}=$ other elephant, not focal elephant, paints) was 229 tested as the factor and time of day as the repeated measure using the repeated measures GLM

230 test. Behaviour recorded during the painting session was analysed, first using a Kruskal-Wallis 231 non-parametric test for heterogeneity, followed by Mann-Whitney U-tests. 


\section{RESULTS}

\section{Stereotyped and abnormal behaviour}

235 Analysis of these scores revealed that there were no main effects of replicates in any of the three 236 conditions $(\mathrm{P}, \mathrm{NP}, \mathrm{OP})\left(\mathrm{F}_{3,9}\right.$ ranged from 0.529 to 1.341 and $\mathrm{P}$ ranged from 0.34 to 0.67$)$. There

237 were no interactions between the time of day and replicates $\left(\mathrm{F}_{6,18}\right.$ ranged from 0.658 to 2.185 and $238 \mathrm{p}$ ranged from 0.09 to 0.68 ). There was a significant effect of time of day on the frequency of 239 performance of stereotyped and abnormal behaviour but only on the day when the focal elephant 240 was selected to paint $\left(\mathrm{F}_{2,6}=6.681, \mathrm{p}=0.028\right.$; Figure $\left.1 \mathrm{a}\right)$.

241 Since 'replicate' was found to have no significant main effect or interaction with 'time of

242 day', means of the replicates were calculated and used in a further analysis using condition as the 243 repeated measure and time of day as the factor. This analysis revealed that there was a non244 significant interaction between condition and time of day $\left(\mathrm{F}_{4,60}=2.452, \mathrm{p}=0.056\right)$. However, the 245 trend towards significance is noted: on the days when the elephants were selected to paint they 246 tended to perform less stereotyped and abnormal behaviour in the morning than on the other days $247 \quad\left(\mathrm{~F}_{2,6}=6.861, \mathrm{p}=0.028\right)$.

Figure $1 \mathrm{~b}$ ) shows the variation between individual elephants for the mean occurrence of stereotyped/abnormal behaviour at three different times of the day. The incidence of stereotyped

250 and abnormal behaviour noted in elephants $\mathrm{A}$ and $\mathrm{B}$ differed to some extent from that of

251 elephants C and D. Stereotypy and abnormal behaviour were found for days when the elephant 252 was not selected to paint as well as on days when the elephant painted. 
A repeated measures GLM test comparing the occurrence of stereotyped/abnormal

254 behaviour at different times (morning, midday and afternoon) between elephants for each

255 condition revealed that there was a significant difference between elephants on the days when

256 they were not selected to paint $\left(\mathrm{F}_{6,18}=7.448, \mathrm{p}=0.008\right)$. Bonferroni pair-wise comparisons

257 revealed that $\mathrm{B}$ and $\mathrm{C}$ were significantly different $(\mathrm{p}=0.039)$ whereas $\mathrm{A}$ and $\mathrm{D}$ tended to be 258 different but it was not significant $(\mathrm{p}=0.059)$.

\section{Other behaviour}

260 Scores of vocalisations, interactive, non-interactive, independent activity and time spent waiting

261 were analysed separately for the three conditions. As there were no significant effects of the 262 replicates for any of the types of behaviour and no significant interactions between time of day 263 and replicate, the means of the replicates were calculated and used in further analyses using 264 condition as the repeated measure and time of day as the factor. The results are presented in 265 Table 1.

The only significant results of these analyses were interactions between condition and

267 time for non-interactive behaviour $\left(\mathrm{F}_{4,60}=2.520, \mathrm{p}=0.050\right)$ and time spent waiting $\left(\mathrm{F}_{4,60}=2.665\right.$, $268 \mathrm{p}=0.041)$. Therefore only these two data sets were examined further.

\section{Non-interactive Behaviour}

270 A further repeated measures GLM test to analyse the data for non-interactive behaviour revealed 271 a significant interaction between condition and time $\left(\mathrm{F}_{2,6}=6.065, \mathrm{p}=0.036\right)$. The level of non-

272 interactive behaviour was higher in the afternoon on days when no elephant painted than on days

273 when the focal elephant was selected to paint $(p=0.041$; Figure $2 a)$. The data for non-interactive

274 behaviour were examined further by comparing individual differences between elephants across

275 the three conditions (Figure $2 \mathrm{~b}$ ). Compared to the other elephants, elephant D displayed much 
276 higher levels of non-interactive behaviour on days when no painting took place, especially in the

277 afternoon. This increase from midday to afternoon when no painting took place was shown in all

278 four replications for D.

279 Overall, the results for the periods outside of the painting session show that elephants C

280 and D performed more stereotyped/abnormal behaviour than elephants A and B, particularly on

281 days when they did not paint. D showed more non-interactive behaviour when no painting took

282 place and more waiting at the door to the indoor area where painting occurs when she was not

283 selected to paint than did the other elephants.

\section{Behaviour during the painting session}

285 During the painting sessions the elephants were given a mean $( \pm$ sem) of $38 \pm 3.49$ commands by 286 the keeper. The mean duration of the painting session was $211 \pm 41 \mathrm{sec}$.

\section{Direction of gaze during painting session}

Elephants $\mathrm{A}$ and $\mathrm{B}$, and to a lesser extent $\mathrm{C}$, spent the majority of the session looking at the keeper standing to their left side (Figure 3 a). D looked at the keeper the least often and spent the

highest percentage of time looking ahead at the canvas, or the person holding the canvas. A

292 Kruskal-Wallis test revealed a significant difference between elephants for time spent with gaze

293 directed at the keeper $\left(\alpha^{2}=9.516, p=0.023\right)$ and gaze directed ahead $\left(\alpha^{2}=10.304, p=0.016\right)$.

\section{Position of ears, head and trunk during painting session}

295 Figure $3 \mathrm{~b}$ ) shows the percentage of time, during the painting session, for which the ears were

296 held in the different positions. Kruskal-Wallis tests revealed that the elephants differed in time spent with their ears forward $\left(\alpha^{2}=8.824, n=4, p=0.032\right)$ and the ears not forward $\left(\alpha^{2}=11.138, n=4\right.$, 
$p=0.011$ ). Elephant A differed significantly from elephants B (ears back, $U=2.000, p=0.046), C$

299 (ears forward, $\mathrm{U}=1.000, \mathrm{p}=0.043$, ears not forward, $\mathrm{U}=.000, \mathrm{p}=0.021$ ) and $\mathrm{D}$ (ears forward,

$300 U=.000, p=0.021$, ears not forward, $U=0.000, p=0.018$, and ears back, $U=2.000, p=0.046$ ). B

301 also differed from $\mathrm{D}$ (ears forward, $\mathrm{U}=1.000, \mathrm{p}=0.043$, ears not forward, $\mathrm{U}=0.000, \mathrm{p}=0.018$ ).

\section{DISCUSSION}

304 Stereotyped and abnormal behaviour

305 The scores of stereotyped behaviour tended to be lower in the morning on the day when the

306 elephant painted than on days when no elephants painted. Post hoc enquiries revealed that

307 keepers selected those elephants showing less stereotyped and abnormal behaviour in the

308 morning to paint that day. Hence, our results reflect this practice.

309 By midday (1 hour before painting) the incidents of stereotyped and abnormal behaviour

310 was similar to that performed at midday on the days when no painting took place. Therefore, the

311 increase in stereotyped and abnormal behaviour between morning and midday on the day when

312 the elephant painted may not have been associated with anticipation of the painting session but,

313 instead, indicated a return to levels typical at that time of day. Hence, despite anticipation of

314 certain events (such as feeding and performing), identified as being a major facilitator of

315 stereotyped behaviour in some circus elephants (Friend \& Bushong, 1996), there was no evidence

316 that the activity of painting had such an effect on the elephants in our study. Moreover, painting

317 had no significant effect on the incidents of stereotyped and abnormal behaviour performed in the 318 afternoon. 
320 higher than those of the other two elephants, especially on days when no elephants painted and at

321 all times of the day sampled. This could, in part, be related to differences in past experience,

322 since performance of stereotypies is known to vary according to age, time spent in captivity and

323 handling by owners/keepers (Mason \& Latham, 2004).

The types of stereotyped and abnormal behaviour that each elephant displayed varied

325 between individuals; for example, trunk swinging and head-bobbing in $\mathrm{C}$, excessive nipple-

326 rubbing in A, and occasional pacing, trunk swinging and weaving in B. Elephant D, in captivity

327 for the longest period of time of the four elephants tested ( $>30 \mathrm{yrs}$ ), performed weaving more

328 than the other elephants. The weaving behaviour could have developed as a coping response to

329 stressors resulting from a prolonged amount of time in captivity (Mason, 1991). Other causes of

330 stress-related behaviour include removal from a familiar environment, long-distance transport

331 and integration into a group of foreign animals (Schmid et al., 2001). These are all events that

332 the elephants at Melbourne Zoo would have experienced at some time.

333 It has also been suggested that elephants may suffer from post-traumatic stress syndrome

334 (Bradshaw et al., 2005) in line with the complex cognitive abilities that have been identified in 335 Asian and African elephants. According to Bradshaw et al. (2005), premature or forced maternal 336 separation, insufficient socialisation, and trauma caused by shock can affect psychological, 337 neurobiological, and behavioural wellbeing of elephants throughout early life and into adulthood.

338 These stressful experiences, many of which are likely to be encountered by elephants in captivity,

339 could influence the development and frequency of stereotyped and abnormal behaviour. 
342 The analyses of non-interactive data revealed a significant effect of time of day. Higher scores of

343 non-interactive behaviour were recorded in the afternoon on the day when no painting took place

344 than on the other days. This indicates that not being given the opportunity to paint may increase

345 non-interactive behaviour. Since Carlstead (1996) has found that reduced interactive behaviour is

346 a response to stressful situations, our results suggest that not being selected to paint may be

347 stressful. Closer examination of the performance of non-interactive behaviour by each elephant

348 revealed that one elephant (D) showed more non-interactive behaviour than the others, especially

349 in the afternoon when no painting took place. More waiting at the door to the area for painting

350 would have been expected at midday before the painting session if the elephants were

351 anticipating the activity of painting. Since this did not happen, it seems that the elephants were

352 not anxious to take part in the painting session, apart from elephant D, who did wait at the door

353 more than usual and performed stereotyped behaviour when she had not been selected to paint

354 and this behaviour increased after the other elephants that did paint returned to the yard. It may

355 have been a coping response that $\mathrm{D}$ had adopted in order to deal with not being selected to paint.

\section{Behaviour during the painting session}

357 During the painting session two elephants (A and B) spent the majority of time looking at the

358 keeper, whereas the others $(C$ and $D)$ spent the majority of time looking forward toward the

359 canvas with their ears facing forward, indicative of high arousal levels (McKay, 1973). It seems,

360 therefore, that elephants $\mathrm{C}$ and $\mathrm{D}$ were attending to the painting itself to a greater extent than

361 elephants A and B, the latter relying on visual and auditory cues from the keeper. Elephants A

362 and B spent much of the painting session following the command for 'trunk up'. This position

363 was held while waiting for the next instruction from the keeper and their gaze was usually

364 directed at the keeper at this time. As a reference guide, a chart from Kuhme's (1963) paper on

365 various head, ear and trunk postures associated with aggression, fear and inhibition in African 
elephants was used to interpret the postures that the elephants were instructed to hold during the

367 painting session. From Kuhme's diagram, the extension of the trunk forward to paint with the

368 ears forward resembles the posture held during increased hostility. The posture with the trunk up

369 resembles conflict between fear, arousal and inhibition. Although these postures were adopted on

370 the keeper's command, they could have influenced the animal's emotional state. Studies have

371 found that when adopting an emotion-specific posture, humans report experiencing the associated

372 emotions of that posture and their preferences and attitudes are influenced (Niedenthal, 2007).

373 The postures that the elephants are instructed to hold could therefore be influencing how they

374 respond to the painting activity, and to the keepers, which might contribute to the differences in

375 behaviour between the four elephants.

\section{Other variables}

378 There was little evidence possible to collect showing that the keeper had a specific role in the

379 behaviour of the elephants and the researchers had no influence on the zoo schedules. The

380 keepers acting as guides for the elephant's painting activities were changed each session, and

381 whoever was on duty administered the sequence of tasks in the same manner. Since we know that

382 elephants recognise individual humans and may develop likes and dislikes to specific people, the

383 human influence on such projects could also form an integral part of any study to eliminate the

384 possibility that elephants respond more to the interaction than to the task.

Importantly, it is also questionable what elephants saw while they were painting. A very

387 detailed examination of the structure and pigments of elephant eyes suggests that elephants may

388 be colour blind. The detailed study by Yokoyama et al. (2005) found that elephants and colour-

389 blind humans (deuteranopes) have identical sets of visual pigments. Potential colour blindness,

390 and the fact that the keepers selected the paint colour, rather than the elephants doing so 
391 themselves, may also affect how stimulating the activity is to the elephant. However, perception

392 of the world by elephants is not entirely clear. A more recent study suggests that elephants can

393 classify humans by odour and garment colour (Bates et al., 2007). This involved testing elephants

394 first using two ethnic groups wearing identical red garments, followed by dressing one ethnic

395 group in white and the other in red. The colour red was selected for the study because this is the

396 colour that Maasai men wear, but it is unfortunate in terms of the findings of Yokoyama et al.

397 (2005) because their findings suggest that red is a colour elephants cannot perceive as a separate

398 colour. However, the white would stand out so clearly that it is not a matter of colour but of light

399 intensity, which made it possible for the elephants to clearly distinguish between the two types of

400 garments. While the title of the paper by Bates et al. (2007) suggests that elephants can

401 distinguish people by colour, this is a little misleading and provides little help for the present 402 study.

403

404 It is of course also possible to relate the activity of painting in elephants to questions about an 405 aesthetic or general artistic sense in (some) animals. The case for an artistic sense has been 406 pleaded for some songbirds and spontaneous responses to rhythm, thought to be unique to 407 humans, have now been shown in some animals, including elephants (Patel \& Inversen, 2006; 408 Schachner et al., 2009, Kaplan, 2009) but far more work, and of a different kind than the context 409 of painting elephants for enrichment, would need to be done to expose the extent and the limits of 410 an artistic sense.

411

412

413 Conclusions

414 
415 The results of this study showed that all four elephants at Melbourne Zoo perform forms of

416 stereotyped behaviour. Since stereotyped behaviour develops as a response to a stressful

417 environment (Selye, 1973; Mason, 1991; Mason \& Latham, 2004), we can propose that the

418 environment in which these elephants live induces stress, or they have been exposed to stressful

419 environments in the past, for example maternal deprivation (Latham \& Mason, 2008). The

420 elephants were found to perform different levels of stereotyped/abnormal behaviour and two

421 distinct pairs were apparent: A/B exhibited lower levels of stereotyped behaviour than C/D.

422 Since previous research has found that the performance of stereotyped behaviour is a means of

423 coping in a sub-optimal environment (Mason, 1991; Mason \& Latham, 2004), and that individual

424 animals performing more stereotyped behaviour generally have lower levels of physiological

425 stress than those that do not perform this behaviour in the same environment (Moberg, 1985;

426 Koolhaas et al., 1999; Matteri et al., 2000), we argue that elephants A and B may be more 427 physiologically stressed than elephants C and D.

One of the key purposes of providing environmental enrichment for captive animals is to

430 reduce the performance of stereotyped behaviour (Swaisgood \& Shepherdson, 2005). The level

431 of stereotyped behaviour of the elephants at Melbourne Zoo was largely unaffected by the 432 activity of painting thus not fulfilling a key purpose of enrichment. They all exhibited stress433 related behaviours. Elephants are wide-ranging animals that require abundant space and social 434 interaction for their physiological and psychological needs, needs that a zoo environment cannot 435 reasonably fulfil. A key purpose of including enrichment activities for captive animals is to at 436 least reduce stress-related behaviour as well as encourage natural behaviour and stimulate the 437 animals. The activity of painting does not appear to address this need adequately. Our results 438 suggest that painting does not improve the welfare of elephants and that its main benefit is the 
439 aesthetic appeal of these paintings to the public and their subsequent sale where a percentage of

440 funds might be donated toward conservation of the species.

441

442 Acknowledgements

443 The research was made possible by the supportive attitude of Melbourne Zoo giving permission

444 for filming and observing the painting sessions and for providing background information on the

445 elephants. The authors gratefully acknowledge their support.

446

447

448

449

450

451

452

453

454

455

456

457

458

459

460

461

462

463

464

465

466

References

467

468 Bates LA, Sayialel KN, Njiraini NW, Poole JH, Moss CJ, Byrne RW. 2007. Elephants classify human 469 ethnic groups by odour and garment colour. Current Biology 17: 1938-1942. 
470

471

472

473

474

475

476

477

478

479

480

481

482

483

484

485

486

487

488

489

490

491

492

493

494

495

496

497

498

499

500

501

502

503

504

505

506

507

508

509

Bates LA, Sayialel K, Njiraini N, Poole JH, Moss CJ, Byrne RW. 2008. Elephants have expectations about the locations of out of-sight family members. Biology Letters 4: 34-36.

Boorer MK. 1972. Some aspects of stereotyped patterns of movements exhibited by zoo animals. International Zoo Yearbook 12: 164-166.

Bradshaw GA, Schore AN. 2007. How elephants are opening doors: Developmental neuroethology, attachment and social context. Ethology 113: 426-436.

Bradshaw GA, Schore AN, Brown JL, Poole JH, Moss CJ. 2005. Elephant Breakdown. Nature 433: 807-807.

Byrne R, Lee PC, Njiraini N, Poole JH, Sayialel K, Sayialel S, Moss CJ. 2008. Do elephants show empathy? Journal of Consciousness Studies 15: 10-11.

Byrne RW, Bates LA, Moss CJ. 2009. Elephant cognition in primate perspective. Comparitive Cognitive Behaviour Reviews 4:1-15.

Carlstead K, Shepherdson D. 2000. Alleviating stress in zoo animals with environmental enrichment. In: Moberg GP, Mensch JA, eds. The Biology of Animal Stress: Basic Principles and Implications for Animal Welfare 337-340.

Carlstead K, 1996. Effects of captivity on the behaviour of wild mammals In: Kleimann DG, Allen ME, Thompson KV, Lumpkin S, eds. Wild Mammals in Captivity: Principles and Techniques. University of Chicago Press, 317-333.

Chevalier-Skolnikoff S, Liska J. 1993. Tool-use by wild and captive elephants. Animal Behaviour 46: 209-219.

Eisenberg JF, McKay GM, Seidensticker J. 1990. In: Seidensticker J, Lumpkin S, eds. Asian Elephants. Friends of the National Zoo and the National Zoological Parks, Washington DC.

Elzanowski A, Sergiel A. 2006. Stereotypic behaviour of a female Asiatic elephant (Elephas maximus) in a zoo. Journal of Applied Animal Welfare Science 9: 223-232.

Foerder P, Galloway M, Barthel T, Moore DE, Reiss, D. 2011. Insightful problem solving in an Asian elephant. PloS one 6: e23251.

Forthman DL, Ogden JJ. 1992. The role of applied behavior analysis in zoo management: Today and tomorrow. Journal of applied behavior analysis 25: 647-652.

Friend TH, Bushong D. 1996. Stereotypic behaviour in circus elephants and the effect of "anticipation" of feeding, watering and performing (Abstract only). Department of Animal Science Texas A \& M University, Texas.

Gilbert B. 1990. Once a malcontent, Ruby has taken up brush and palette. Smithsonian 21: 40-46.

Gordon JA. 1966. Elephants do think. African Wildlife 20:75-79.

Hart BL, Hart LA, McCoy M, Sarath CR. 2001. Cognitive behaviour in Asian elephants: use and modification of branches for fly switching. Animal Behaviour 62: 839-847.

Hart BL, Hart LA, Pinter-Wollman N. 2008. Large brains and cognition: Where do elephants fit in? Neuroscience Biobehaviour Reviews 32:86-98.

Hart BL, Hart LA. 1994. Fly switching by Asian elephants: Tool-use to control parasites. Animal Behaviour 48: 35-45.

Hediger H. 1950. Wild Animals in Captivity. London: Butterworths. 
510

511

512

513

514

515

516

517

518

519

520

521

522

523

524

525

526

527

528

529

530

531

532

533

534

535

536

537

538

539

540

541

542

543

544

545

546

547

548

549

Jachowski DS, Slotow R, Millspaugh JJ. 2013. Corridor use and streaking behavior by African elephants in relation to physiological state. Biological Conservation 167: 276-282.

Kaplan G. 2009. Animals and music: Between cultural definitions and sensory evidence. Sign Systems Studies 37(3/4)

Kiley-Worthington M. 1990. Animals in Circuses and Zoos: Chiron's World? Little Eco-Farms Publishing, Essex.

Koolhaas JM, Korte SM, DeBoer SF, van Der Vegt BJ, van Reenen CG, Hopster H, DeJong IC, Ruis MAW,Blokhius HJ. 1999. Coping styles in animals: current status in behaviour and stress physiology. Neuroscience and Biobehavioural Reviews 23: 925-935.

Kuhme W. 1963. Ethology of the African elephant in captivity (Loxodonta africana). International Zoo Yearbook 4: 113-121.

Kurt F, Garai M. 2002. Stereotypies in captive Asian elephants- a symptom of social isolation In: Schwammer HM, Foose TJ, Fauraker M,Olson D, eds. A Research Update on Elephants and Rhinos 57-63.

Lair RC. 1997. Gone Astray: The Care and Management of the Asian Elephant in Domesticity. Food Agriculture Organisation United Nations, Rome.

Langbauer W. 2000. Elephant communication. Zoo Biology 19: 425-445.

Latham NR, Mason GJ. 2008. Maternal deprivation and the development of stereotypic behaviour. Applied Animal Behaviour Science 110:84-108.

Mason GJ, Latham NR. 2004. Can't stop, won't stop: is stereotypy a reliable animal welfare indicator? Animal Welfare 13: 57-69.

Mason GJ. 1991. Stereotypies: A critical review. Animal Behaviour 41: 1015-1037.

Matteri RL, Carroll JA,Dyer CJ. 2000. Neuroendocrine responses to stress. In: Moberg GP and Mensch JA, eds. The Biology of Animal Stress: Basic Principles and Implications for Animal Welfare 4376.

McComb K, Shannon G, Sayialel KN, Moss CJ. 2014. Elephants can determine ethnicity, gender, and age from acoustic cues in human voices. Proceedings of the National Academy of Sciences 111: 5433-5438.

McKay GM. 1973. Behaviour and Ecology of the Asiatic Elephant in South-eastern Ceylon. Smithsonian Contribution to Zoology 125.

Mellen J, MacPhee MS. 2005. Philosophy of environmental enrichment: Past, present and future. Zoo Biology 20: 211-226.

Moberg GP. 1985. Biological response to stress: key to assessment of animal well-being? In: Animal stress Springer New York 27-49.

Moss CJ. 1988. Elephant Memories: Thirteen Years in the Life of an Elephant Family. Fawcett Columbine, New York.

Moss CJ, Poole JH. 1983. Relationships and social structure of African elephants. In: Hinde RA, ed. Primate Social Relationships: An Integrated Approach. Oxford: Blackwell Scientific 315-325.

Moss CJ. 1998. Elephant Memories. Elm Tree Books, London.

Nair S, Balakrishnan R, Seelamantula CS, Sukumar R. 2009. Vocalizations of wild Asian elephants 
(Elephas maximus): Structural classification and social context. Journal of Acoustic Society of America 126: 2768-2778.

Niendenthal P. 2007. Embodying Emotion. Science 316: 1002-1005.

Odberg FO. 1987. Behavioural responses to stress in farm animals In: Wiepkema PW, Van Adrichem M, eds. Biology and Stress in Farm animals: An integrative Approach 135-150.

Patel AD, Iversen JR, Bregman MR, Schulz I. 2009. Experimental evidence for synchronization to a musical beat in a nonhuman animal. Current Biology 19: 827-830.

Payne KB. 2003. Sources of social complexity in the three elephant species. In: de Waal FBM, Tyack PL, eds. Animal Social Complexity: Intelligence, Culture and Individualised Society. Harvard University Press, Cambridge 57-86.

Plotnik JM, de Waal FBM, Reiss D. 2006. Self-recognition in an Asian elephant. Proceedings National Academy of Science 103:17053-17057.

Plotnik JM, de Waal F, Moore D, Reiss D. 2010. Self-recognition in the Asian elephant and future directions for cognitive research with elephants in zoological settings. Zoo biology 29: 179191.

Plotnik JM, Lair R, Suphachoksahakun W, de Waal, FB. 2011. Elephants know when they need a helping trunk in a cooperative task. Proceedings of the National Academy of Sciences 108: 51165121.

Poole J. 1996. Coming of Age with Elephants. Hyperion, New York.

Poole JH, Granli P. 2011. Signals, gestures, and behavior of African elephants. The Amboseli Elephants: A Long-Term Perspective on a Long-Lived Mammal 109-124.

Poole JH, Granli, PK. 2009. Elephant voices gestures database. Available at http://www.elephantvoices.org (Accessed 10/03/2014).

Poole JH, Moss CJ. 2008. Elephants and Ethics, In: Wemmer C, Christen CA, eds. Johns Hopkins University Press, Baltimore 69-98.

Poole JH, Payne KB, Langbauer WR,Moss C. 1988. The social contexts of some very low frequency calls of African elephants. Behavioural Ecology and Socio-Biology 22: 385-392.

Rees PA. 2004. Low environmental temperature causes an increase in stereotypical behaviour in captive Asian elephants. Journal of Thermal Biology 29: 37-43.

Rensch, B. 1957. The intelligence of elephants. Scientific American 196: 44-49.

Rogers LJ, Kaplan G. 2007. Elephants that paint, birds that make music: Do animals have an aesthetic sense? In: Read CA, ed. Cerebrum: Emerging Ideas in Brain Science, Dana Press, New York 137150.

Samansiri KAP, Weerakoon DK. 2007. Feeding behaviour of Asian elephants in the northwestern region of Sri Lanka. GAJAH 27.

Schachner A, Brady TF, Pepperberg IM, Hauser MD. 2009. Spontaneous motor entrainment to music in multiple vocal mimicking species. Current Biology 19: 831-836.

Schmid J, Heisterman M, Gansloßer U, Hodges JK. 2001. Introduction of foreign female Asian elephants (Elephas maximus) into an existing group: Behavioural reactions and changes in cortisol levels. Animal Welfare 10: 357-372. 
590 Schulte BA. 2000. Social structure and helping behavior in captive elephants. Zoo Biology 19:447-459.

591 Selye H. 1973. The evolution of the stress concept. American Science 61: 692-699.

592 Sevenich M, Upchurch B, Mellen J. 1998. The science of animal management: evaluating the effects of 593 training and enrichment on elephant behavior. Journal of Elephant Managers Association 9:201594205.

595 Shepherdson D. 1999. Environmental enrichment for elephants: current status and future directions. 596 Journal of Elephant Managers Association 10:69-77.

597 Shoshani J, Kupsky WJ, Marchant GH. 2006. Elephant brain. Part I: Gross morphology, functions, 598 comparative anatomy, and evolution. Brain Research Bulletin 70:124-157.

600

601

602

603

604

605

606

607

Wittemyer G, Douglas-Hamilton I, Getz WN. 2005. The socioecology of elephants: analysis of the processes creating multi-tiered social structures. Animal Behaviour 69: 1357-1371.

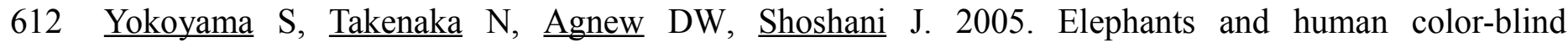
deuteranopes have identical sets of visual pigments. Genetics 170: 335-344 
626

627

628

629

ป 630

$\supseteq 631$

$\sum^{\bar{\sigma}} \quad 632$

기

$\sum_{10}$

$>$

$\simeq$

-

(a)

(a)

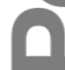

PeerJ reviewing PDF | (v2014:05:2130:1:2:NEW 15 Jun 2014) 


\section{Table 1 (on next page)}

Table of results for GLM analysis

Table 1 - The results of analysis using repeated measures GLM for each behaviour before and after painting sessions. Significant effects are highlighted in bold. 


\begin{tabular}{|c|c|c|c|}
\hline Behaviour & $\begin{array}{l}\text { Main } \\
\text { Effect } \\
\text { Condition } \\
\end{array}$ & $\begin{array}{l}\text { Main } \\
\text { Effect } \\
\text { Time } \\
\end{array}$ & $\begin{array}{l}\text { Interaction b/w } \\
\text { Condition \& Time }\end{array}$ \\
\hline Stereotyped/Abnormal & $\begin{array}{l}\mathrm{F}_{2,30}=1.003 \\
\mathrm{P}=0.379\end{array}$ & $\begin{array}{l}\mathrm{F}_{2,30}=2.434 \\
\mathrm{P}=0.105\end{array}$ & $\begin{array}{l}F_{4,60}=2.452 \\
P=0.056\end{array}$ \\
\hline Vocalisations & $\begin{array}{l}\mathrm{F}_{2,22}=0.007 \\
\mathrm{P}=0.993\end{array}$ & $\begin{array}{l}\mathrm{F}_{2,22}=1.674 \\
\mathrm{P}=0.210\end{array}$ & $\begin{array}{l}\mathrm{F}_{4,44}=0.062 \\
\mathrm{P}=0.993\end{array}$ \\
\hline Interactive & $\begin{array}{l}\mathrm{F}_{2,30}=1.003 \\
\mathrm{P}=0.379\end{array}$ & $\begin{array}{l}\mathrm{F}_{2,30}=0.885 \\
\mathrm{P}=0.423\end{array}$ & $\begin{array}{l}\mathrm{F}_{4,60}=0.994 \\
\mathrm{P}=0.418\end{array}$ \\
\hline Non-Interactive & $\begin{array}{l}\mathrm{F}_{2,30}=1.704 \\
\mathrm{P}=0.199\end{array}$ & $\begin{array}{c}\mathrm{F}_{2,30}=2.261 \\
\mathrm{P}=0.122\end{array}$ & $\begin{array}{l}\mathrm{F}_{4,60}=2.520 \\
\mathbf{P}=\mathbf{0 . 0 5 0}\end{array}$ \\
\hline Exploration & $\begin{array}{l}\mathrm{F}_{2,30}=.422 \\
\mathrm{P}=0.660\end{array}$ & $\begin{array}{l}\mathrm{F}_{2,30}=0.466, \\
\mathrm{P}=0.632\end{array}$ & $\begin{array}{l}F_{4,60}=1.196 \\
P=0.322\end{array}$ \\
\hline Waiting & $\begin{array}{l}\mathrm{F}_{2,30}=2.091 \\
\mathrm{P}=.141\end{array}$ & $\begin{array}{l}\mathrm{F}_{2,30}=2.634 \\
\mathrm{P}=0.088\end{array}$ & $\begin{array}{l}F_{4,60}=2.665 \\
\mathbf{P}=\mathbf{0 . 0 4 1}\end{array}$ \\
\hline
\end{tabular}




\section{Figure 1}

Occurrence of stereotyped and abnormal behaviour

Fig 2 - The mean number of events per elephant ( \pm sem) per 30 minutes of stereotyped plus abnormal behaviour at A) the three different times of the day and in the three conditions. $P$, the elephant scored engages in the activity of painting; NP, days recorded on which no elephant paints; OP, other elephants paint but not the focal elephant being scored. Each elephant was recorded on twelve days (four repeats for each type of day). Note the lower score in the morning of the day when the elephant is selected to paint and the increase at midday and B) Mean occurrence ( \pm sem) for the individual elephants of stereotyped and abnormal behaviour on days when the focal elephant was not selected to paint. The data are for mean overall number of events per elephant per 30 minutes (three times a day- morning, midday and afternoon) repeated over four days. A, B, C and D refers to the four elephants studied. 
A)

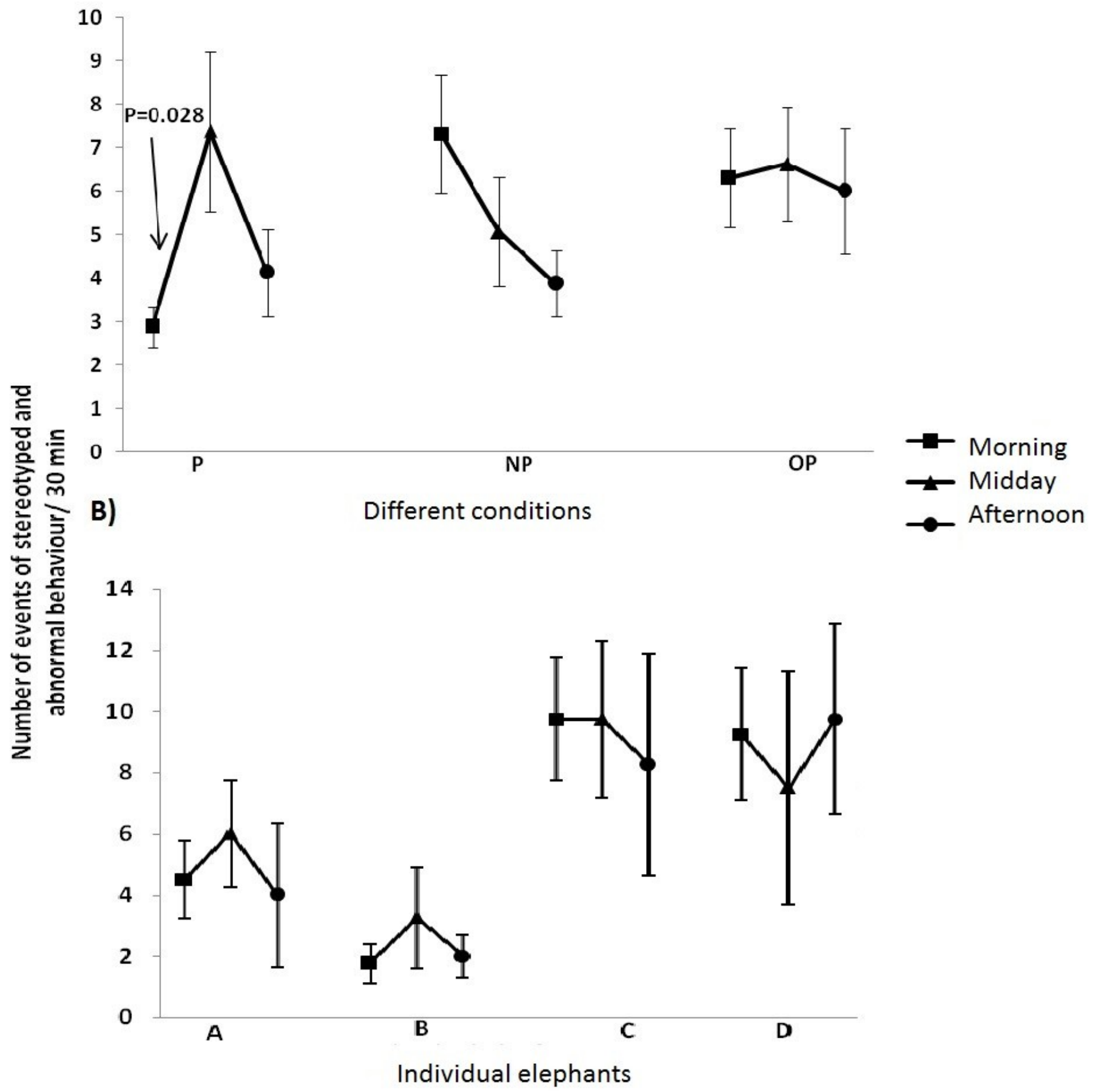




\section{Figure 2}

Non-interactive behaviour

Fig 2 - Mean scores ( \pm sem) of non-interactive behaviour at A) different times of the day over the conditions are presented. P, NP and OP refer to the three conditions as in Figure 1 and B) behaviour for each individual elephant on days when no painting took place. A, B, C and D refer to the four elephants studied. 
A)

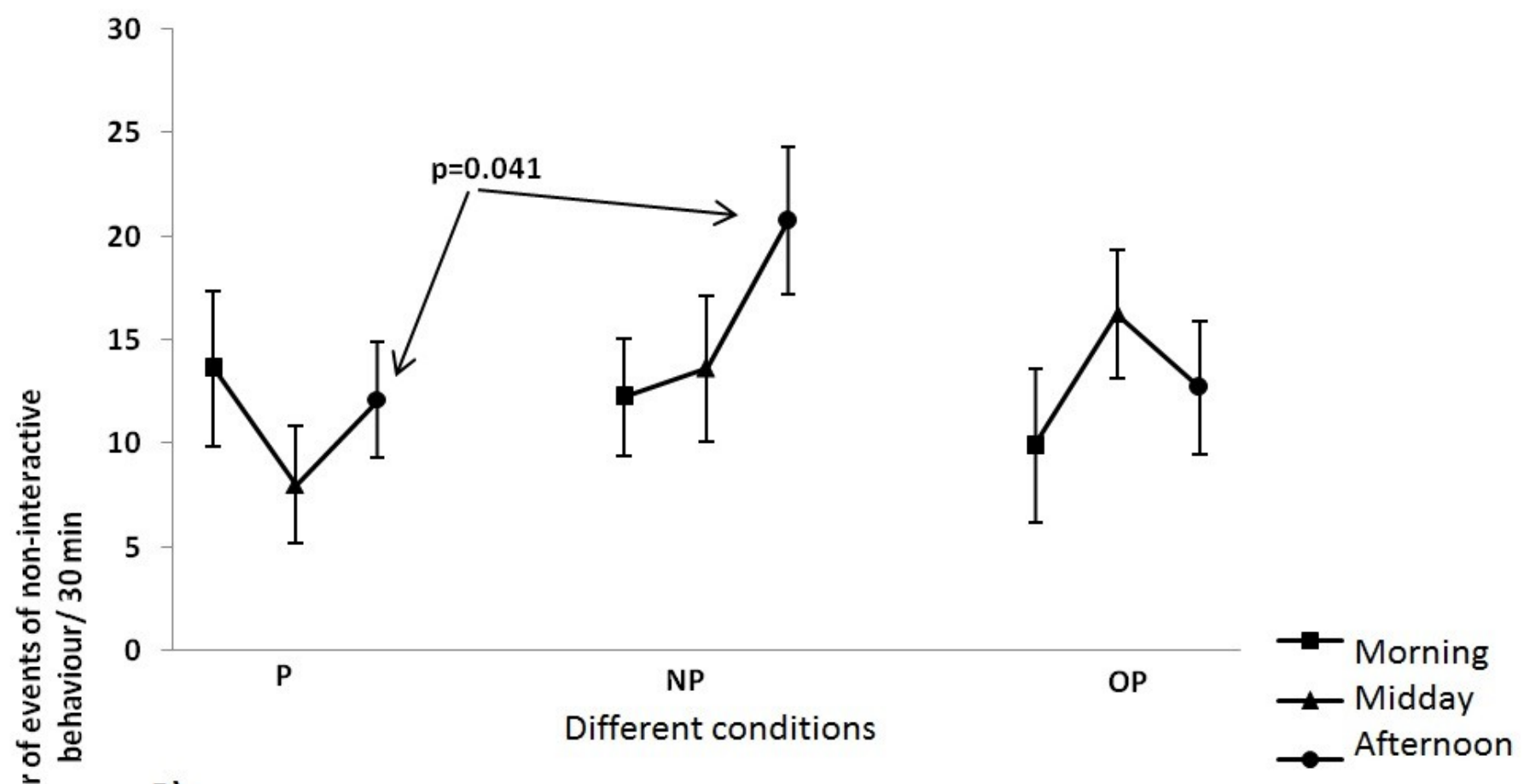

B)

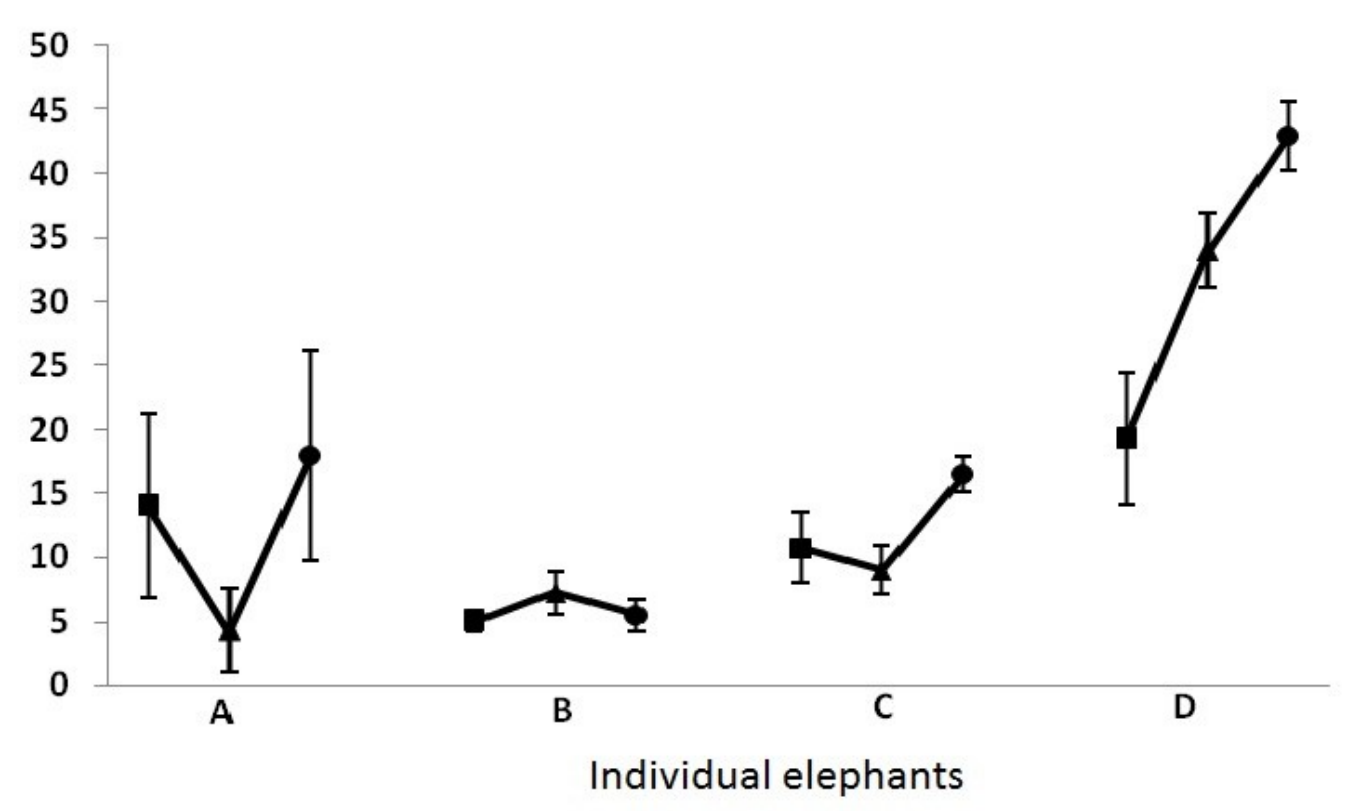




\section{Figure 3}

Gaze direction and ear position during painting

Fig 3 -

Mean percentage of time $( \pm$ sem)

spent

with A) gaze following a particular direction.

Percentages were calculated by dividing mean time gazing in each

direction by total time for which the direction of gaze could be scored. Note the percentage of time that elephant $D$

spent looking ahead. Columns marked 'a'

differ significantly from those marked ' $b$ ' $(p=<.05)$. The three sections of columns are, respectively, from the left to the right; looking at the keeper, looking

forward and looking at the scorer and B) [b]

[b] Position of the ears during a painting session, presented as percentage of

time spent with ears in each position. Significant differences between

elephants are shown. $\mathbf{a}$ and $\mathbf{b}$ indicate significant differences between elephants. $\mathbf{a}$ *

and $\mathbf{b}$ * indicate that elephant $B$

differed from elephant $D$ in time spent with ears not forward. The four sections of columns, from left to

right respectively are; forward ear position (45- $90^{\circ}$ from body), not forward ( $<45^{\circ}$ from body), flapping, and back ( $<10 \mathrm{~cm}$ from body). 
A)

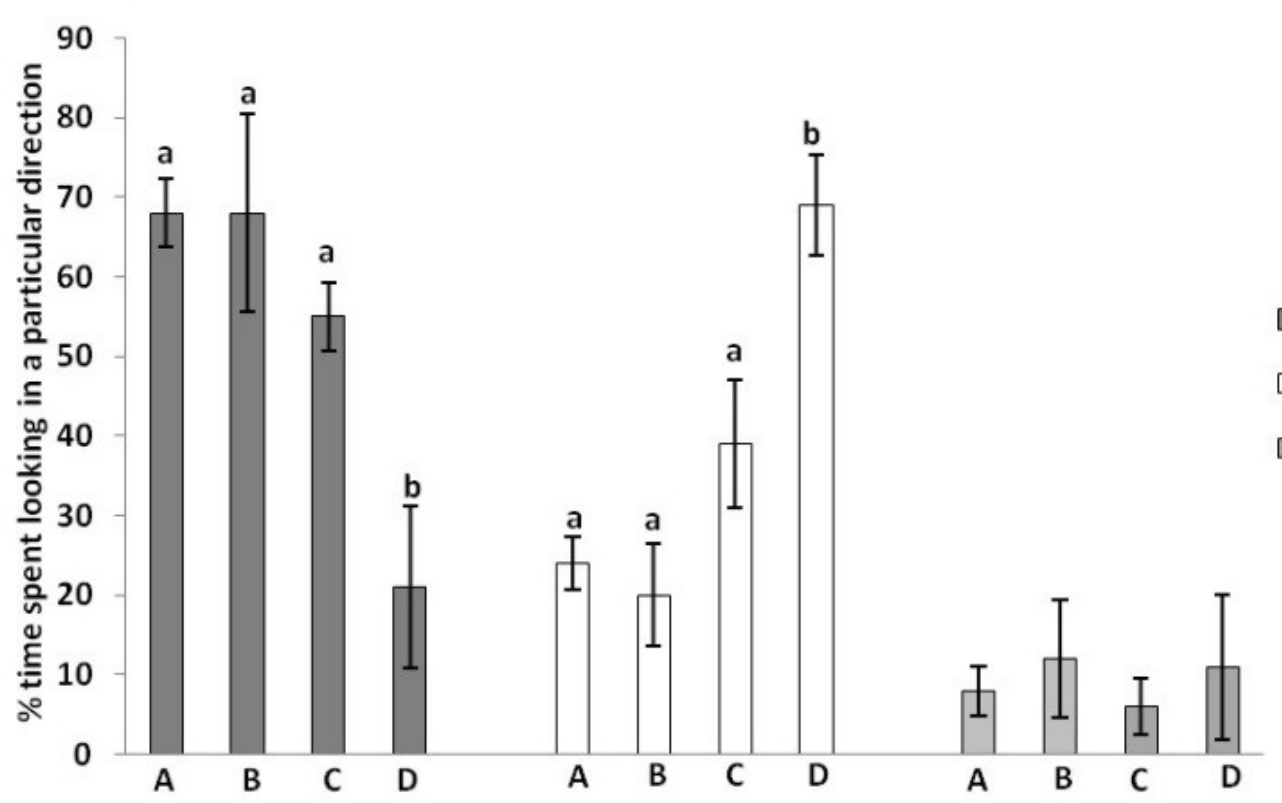

B)

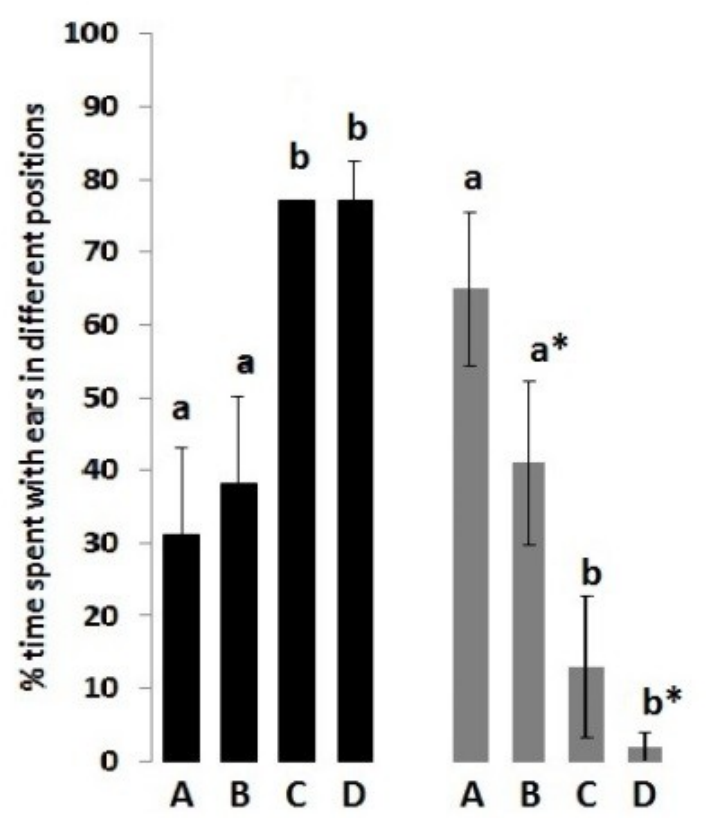

Individual elephants

Looking at keeper

$\square$ Looking ahead

$\square$ Looking at scorer

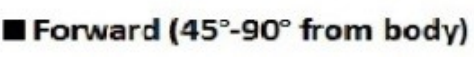
not forward $\left(<45^{\circ}\right.$ from body) $\square$ Flapping - Back (<10 cm from body) $\stackrel{a}{a}=b$

A B C D 


\section{Figure 4}

Image of an elephant painting

Fig 4 -

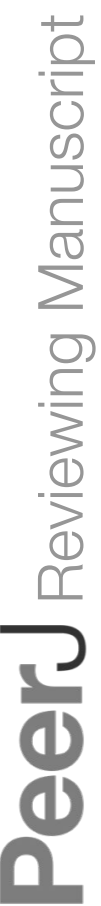

[p] Image of elephant painting at

Melbourne Zoo. [p]

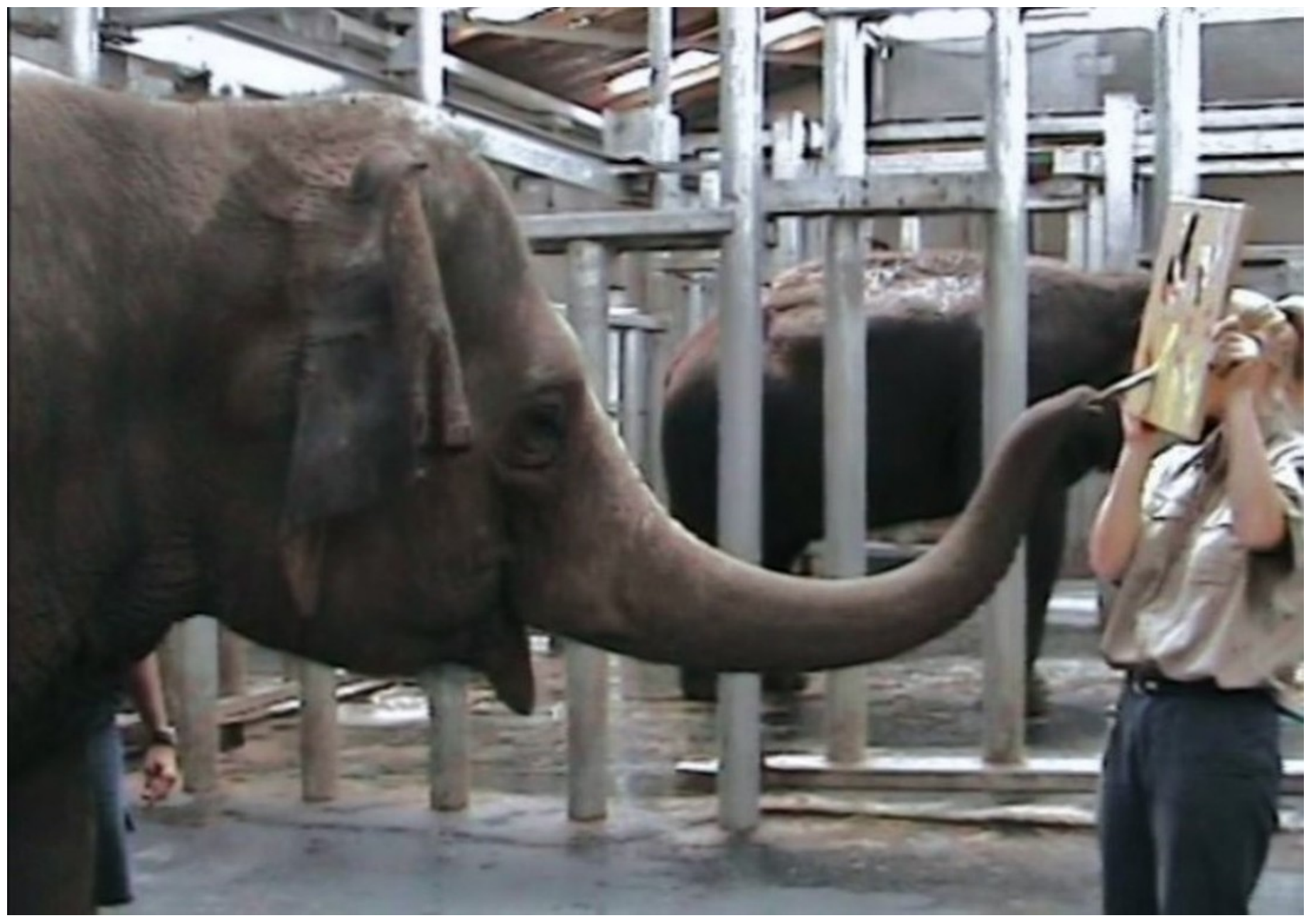

